\title{
NOTES
}

\section{Synthesis of Poly(DL-4-oxohomophenylalanine)}

\author{
Tadao HAYAKAwA, Katsuhiko InOUYE, and Tomohiko ITOH \\ Institute of High Polymer Research, Faculty of Textile Science \\ and Technology, Shinshu University, Ueda 386, Japan
}

(Received May 25, 1988)

KEY WORDS Synthesis / Poly(DL-4,4'-ethylenedioxyhomophenylalanine) /
Poly(DL-4-oxohomophenylalanine) / Infrared Spectra /

The common $\alpha$-amino acids in protein gave polyamino acids upon polymerization of the corresponding $\alpha$-amino acid $N$-carboxyanhydride (NCA). However, the preparation of poly (oxoamino acids) and derivatives has not been reported yet.

Some 4-oxoamino acids, such as 4-oxonorleucine ${ }^{1}$ found in the hydrolysates of a polysaccharide from Citrobacter freundii, 4oxohomotyrosine ${ }^{2}$ in the degradation product of echinocandin B and kynurenine in the metabolite ${ }^{3}$ and photochemical ${ }^{4}$ degradation of tryptophan, have been discovered in nature.

In the present paper we report the synthesis of the polymer of DL-4-oxohomophenylalanine containing a carbonyl group in its side chain analogous to the above oxoamino acids. The carbonyl group was protected by ethylene ketal. The removal of ethylene ketal groups from the protected polymer was performed by hydrogen bromide in glacial acetic acid. The polymer was identified by means of infrared (IR) measurement and elemental analysis.

\section{RESULTS AND DISCUSSION}

The synthetic route of poly(DL-4-oxohomophenylalanine) (V) is summarized in Scheme 1.

4-Oxohomophenylalanine was prepared by the acetoamidomalonic ester pathway. The carbonyl group of Z-derivative (I) was pro- tected as an ethylene ketal by reaction with ethylene glycol. The product II was then converted into the NCA (III) by the usual method. The NCA was polymerized to poly(DL-4,4'ethylenedioxyhomophenylalanine) (IV) which was subsequently converted into poly(DL-4oxohomophenylalanine) (V) by treating it with hydrogen bromide in glacial acetic acid. Polymer IV shows low intrinsic viscosity as seen in the experimental section, suggesting that it is not high molecular weight product with the ordered structure probably because of either the optically inactive amino acid or the steric hindrance in the side chain. The polymers IV and $\mathrm{V}$ showed similar solubilities in the tested solvents. They were soluble in dimethylformamide (DMF), methylene chloride, chloroform, dichloroacetic acid, trifluoroacetic acid, and hot acetic acid, and were insoluble in ether, ethanol, methanol, acetone, and water.

The IR absorption spectra of polymers IV and $\mathrm{V}$ are shown in Figure 1. These polymers showed IR absorption, at $3300 \mathrm{~cm}^{-1}$ (amide A), $1660-1650 \mathrm{~cm}^{-1}$ (amide I) and $1550 \mathrm{~cm}^{-1}$ (amide II), which were related to the specific absorption of polypeptide. The polymer IV also showed absorption at $1030 \mathrm{~cm}^{-1}$ which corresponded to the ether group in its side chains. The polymer $\mathrm{V}$ showed other additional absorptions at $1700 \mathrm{~cm}^{-1}$ and 1380 $\mathrm{cm}^{-1}$ which corresponded to carbonyl group. 
T. Hayakawa, K. INOUYe, and T. Itoh

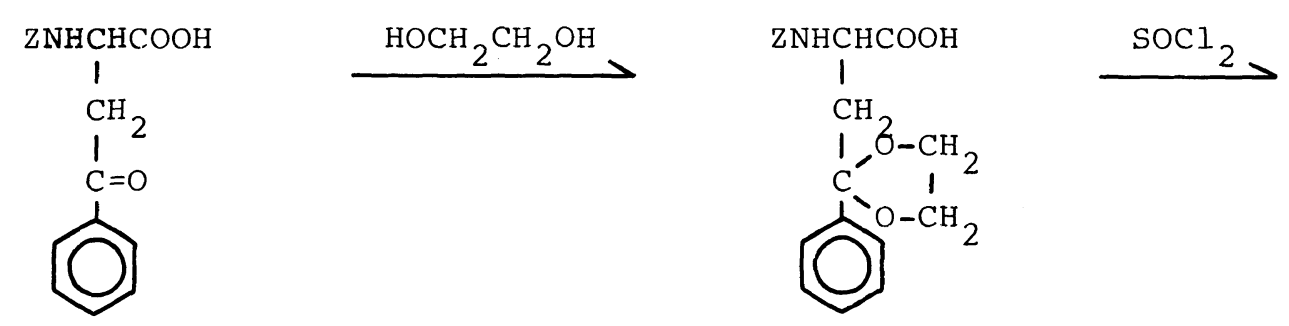

(I)<smiles>O=C1CO[C@H](CC2(c3ccccc3)OCCO2)N1</smiles>

(III)

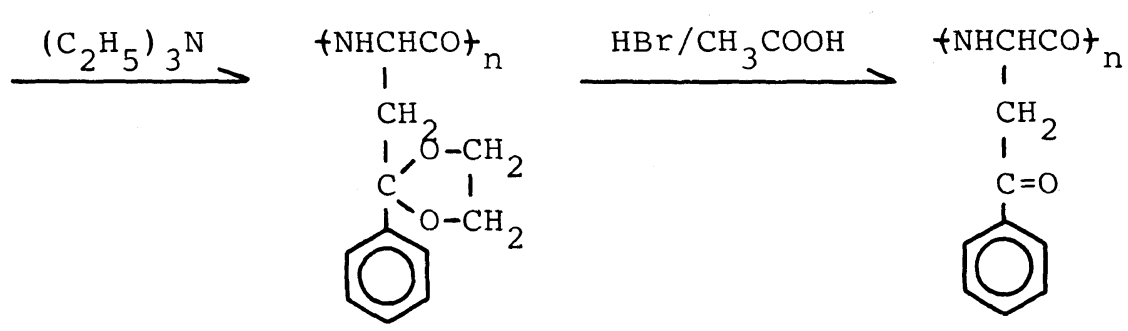

(IV)

Scheme 1. The synthetic route of poly(DL-4-oxohomophenylalanine).

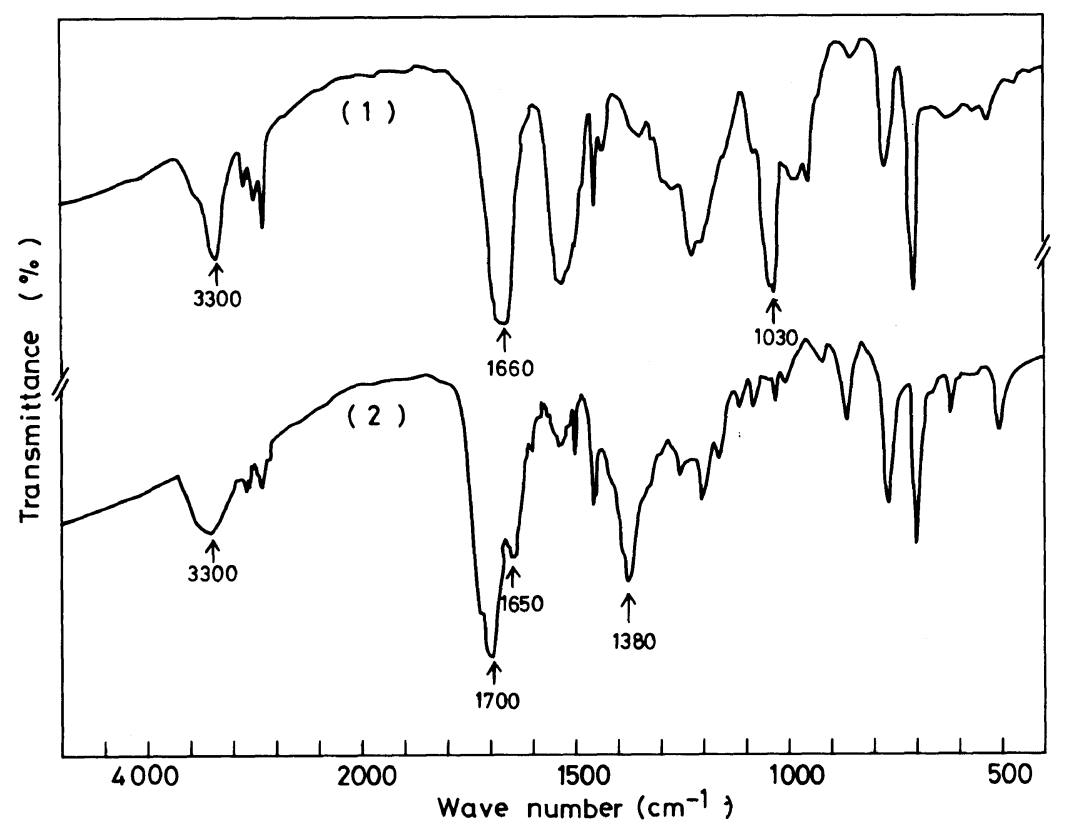

Figure 1. Infrared absorption spectra of poly(DL-4,4'-ethylenedioxyhomophenylalanine) (1) and poly(DL-4-oxohomophenylalanine) (2). 
The ether bond of the starting polypeptide at $1030 \mathrm{~cm}^{-1}$ disappeared.

\section{EXPERIMENTAL}

\section{Materials}

Diethyl 2-acetamido-2-phenacylmalonate. To a solution of sodium diethyl acetamidomalonate $(32.7 \mathrm{~g})$ in $250 \mathrm{ml}$ of dry benzene was added phenacylbromide $(25.0 \mathrm{~g})$. The mixture was heated for $20 \mathrm{~h}$ under reflux. The sodium bromide precipitated was filtered, and the filtrate was evaporated to dryness. The residue was treated with $200 \mathrm{ml}$ of ether. The crystals formed were collected by filtration and purified by recrystallization from an ethyl acetate solution with the addition of ether. Yield $24.1 \mathrm{~g}\left(53.9^{\circ}\right), \mathrm{mp} 119-120^{\circ} \mathrm{C}$.

Anal. Calcd for $\mathrm{C}_{17} \mathrm{H}_{21} \mathrm{O}_{6} \mathrm{~N}: \mathrm{C}, 60.89 \%$; $\mathrm{H}, 6.31 \%$; N, $4.18 \%$. Found: C, $60.68 \%$; H, $6.19 \%$; N, $4.19 \%$.

DL-4-Oxohomophenylalanine hydrochloride. To $150 \mathrm{ml}$ of $6 \mathrm{~N} \mathrm{HCl}$ was added diethyl 2acetamido-2-phenacylmalonate $(20.8 \mathrm{~g})$, and the suspension was heated for $4 \mathrm{~h}$ under reflux. The solution was evaporated to dryness under reduced pressure. The residue was treated with cold water and the cyrstals were collected by filtration. It was purified by recrystallization from an ethanol solution with the addition of ether. Yield $13.1 \mathrm{~g}(91.5 \%)$, mp $198-200^{\circ} \mathrm{C}$.

Anal. Calcd for $\mathrm{C}_{10} \mathrm{H}_{12} \mathrm{O}_{3} \mathrm{NCl}$ : C, $52.30 \%$; $\mathrm{H}, 5.27 \%$; N, $6.10 \%$. Found: C, $52.34 \%$; $5.32 \%$; N, $6.16 \%$.

Benzyloxycarbonyl (Z)-DL-4-oxohomophenylalanine $(I)$. I was prepared by treatment of DL-4-oxohomophenylalanine $\mathrm{HCl}$ with benzyloxycarbonyl chloride in the usual way. The resultant Z-derivative was purified by recrystallization from an ethyl acetate solution with the addition of $n$-hexane. Yield $83.6 \%, \mathrm{mp}$ $118-120^{\circ} \mathrm{C}$.

Anal. Calcd for $\mathrm{C}_{18} \mathrm{H}_{17} \mathrm{O}_{5} \mathrm{~N}: \mathrm{C}, 66.05 \%$; $\mathrm{H}, 5.23 \%$; N, $4.28 \%$. Found: C, $65.88 \%$; H, $5.18 \% ; \mathrm{N}, 4.08 \%$.

Z-DL-4,4'-ethylenedioxyhomophenylalanine
(II). To a solution of Z-derivative (I) $(5.0 \mathrm{~g})$ in $300 \mathrm{ml}$ of benzene were added $50 \mathrm{ml}$ of ethylene glycol and $p$-toluenesulfonic acid $(0.3 \mathrm{~g})$. The solution was refluxed in a flask equipped with a Deen-Stark separator. After 19 h, benzene was removed under reduced pressure. To a residual solution were added $200 \mathrm{ml}$ of water followed by extraction with ethyl acetate. The organic layer was washed with water and dried over sodium sulfate. After the solution was evaporated to dryness, the residual product was dissolved in $18 \mathrm{ml}$ of acetone and $18 \mathrm{ml}$ of $1 \mathrm{~N} \mathrm{NaOH}$. The mixture was stirred for $12 \mathrm{~h}$ at room temperature. After acetone was removed under reduced pressure, the unreacted material was extracted with ethyl acetate. The water layer was acidified to $\mathrm{pH} 3$ with $1 \mathrm{~N} \mathrm{HCl}$. The crystals precipitated were filtered, dried and purified by recrystallization from an ethyl acetate solution with the addition of $n$-hexane. Yield $4.68 \mathrm{~g}\left(82.5^{\circ}\right), \mathrm{mp} 135-136^{\circ} \mathrm{C}$.

Anal. Calcd for $\mathrm{C}_{20} \mathrm{H}_{21} \mathrm{O}_{6} \mathrm{~N}: \mathrm{C}, 64.68 \%$; $\mathrm{H}, 5.70 \%$; N, $3.77 \%$. Found: C, $64.56 \%$; H, $5.51 \% ; \mathrm{N}, 3.81 \%$.

$\mathrm{DL}-4,4^{\prime}$-ethylenedioxyhomophenylalanine $N C A(I I I)$. A solution of the above compound II $(1.5 \mathrm{~g})$ in dioxane $(20 \mathrm{ml})$ was treated with thionyl chloride $(3 \mathrm{ml})$ at $50^{\circ} \mathrm{C}$ in the usual way. The resultant NCA was purified by recrystallization from an ethyl acetate solution with the addition of ether. Yield $0.55 \mathrm{~g}$ (51.7 $\%$ ), mp $158-160^{\circ} \mathrm{C}$.

Anal. Calcd for $\mathrm{C}_{13} \mathrm{H}_{13} \mathrm{O}_{5} \mathrm{~N}$ : C, $59.31 \%$; $\mathrm{H}, 4.98 \%$; N, $5.32 \%$. Found: C, $59.19 \%$; H, $4.80 \%$; N, $5.34 \%$.

The product showed IR absorptions at 1855 and $1785 \mathrm{~cm}^{-1}$ due to cyclic mixed anhydride.

Poly(DL-4,4'-ethylenedioxyhomophenylalanine) (IV). The above NCA $(0.42 \mathrm{~g})$ was dissolved in a chlorobenzene $(1.0 \mathrm{ml})-\mathrm{DMF}$ $(0.3 \mathrm{ml})$ mixture and $n$-hexylamine was added as an initiator $([\mathrm{M}] /[\mathrm{I}]=100)$. The mixture was polymerized at $50-60^{\circ} \mathrm{C}$ for 3 days. The polymerization reaction proceeded in homogeneous solution. The resultant mixture was poured into methanol to precipitate the poly- 
mer. The precipitate was then filtered and washed with methanol. Yield $0.33 \mathrm{~g}(94.3 \%)$.

Anal. Calcd for $\left(\mathrm{C}_{12} \mathrm{H}_{13} \mathrm{O}_{3} \mathrm{~N}\right)_{\mathrm{n}}$ : C, $65.74 \%$; $\mathrm{H}, 5.98 \%$; N, 6.39\%. Found: C, $65.77 \%$; $5.87 \%$; N $6.40 \%$.

The polypeptide had an intrinsic viscosity $[\eta]$ of $0.06 \mathrm{dlg}^{-1}$ in DMF at $25^{\circ} \mathrm{C}$.

Poly(DL-4-oxohomophenylalanine) ( $V$ ). To a solution of the above protected polymer IV $(200 \mathrm{mg})$ in glacial acetic acid $(10 \mathrm{ml})$ was added $25 \% \mathrm{HBr}$ in acetic acid $(5 \mathrm{ml})$. After the mixture was stirred for $2 \mathrm{~h}$ at room temperature, $100 \mathrm{ml}$ of dry ether were added. The precipitate was filtered and washed with ether, ethanol and water. Yield $130 \mathrm{mg}(81.3 \%)$.

Anal. Calcd for $\left(\mathrm{C}_{10} \mathrm{H}_{9} \mathrm{O}_{2} \mathrm{~N}\right)_{\mathrm{n}}$ : C, $68.56 \%$; $\mathrm{H}, 5.18 \%$; N, $8.00 \%$. Found: C, $68.95 \%$; $4.90 \%$; N, $8.04 \%$.

\section{Methods}

Elemental analyses were carried out with a Yanagimoto $\mathrm{CHN}$ corder MT-2 instrument. The viscosity was measured in DMF at $25^{\circ} \mathrm{C}$ using an Ubbelohde viscometer. The IR measurements were performed on IR A 302 in- strument (Japan Spectroscopic Co., Ltd.).

\section{CONCLUSIONS}

The carbonyl group of Z-4-oxohomophenylalanine (II) is protected by the ethylene ketal. Poly(DL-4,4'-ethylenedioxyhomophenylalanine) (IV) was obtained by the NCA method. Subsequent removal of protected groups from IV by treatment with hydrogen bromide in glacial acetic acid gave poly(DL-4oxohomophenylalanine) (V). These polymers were identified by IR measurements and elemental analyses. A study of the polymerization of other 4-oxoamino acids is now in progress.

\section{REFERENCES}

1. G. T. Barry, F. Chen, and E. Roark, J. Gen. Microbiol., 33, 95 (1963).

2. W. Keller-Schierlein and B. Toos, Helv. Chim. Acta, 63, 250 (1980).

3. Y. Kotake and T. Masayama, Z. Physiol. Chem., 243, 237 (1936).

4. W. E. Savige, Aust. J. Chem., 24, 1285 (1971). 